\title{
A System Dynamics Model for Analyzing Researchers' Behavior in Fee-based Online Knowledge Markets
}

\author{
Mostafa Jafari \\ Department of Industrial Engineering, Iran University of Science and Technology (IUST) \\ Narmak, PO box 1684613114, Tehran, Iran \\ Tel: 98-21-7391-3000Ｅ-mail: jafari@iust.ac.ir \\ Roozbeh Hesam Amiri (Corresponding author) \\ Department of Industrial Engineering, Iran University of Science and Technology (IUST) \\ Narmak, PO box 1684613114, Tehran, Iran \\ Tel: 98-912-5356-487Ｅ-mail: amiri_r@ind.iust.ac.ir \\ Atieh Bourouni \\ Department of Industrial Engineering, Iran University of Science and Technology (IUST) \\ Narmak, PO box 1684613114, Tehran, Iran \\ E-mail: bourouni@ind.iust.ac.ir
}

\begin{abstract}
The purpose of this paper is to develop a simple dynamic model to analyze researchers' interest in answering questions for an online question and answer (Q\&A) knowledge market. With use of a System Dynamics model, an online knowledge market can be modeled as a marketplace where consumers ask and researchers answer questions to make knowledge transactions. In this market, consumers price their questions to acquire answers, and a company maintains the online knowledge market by determining the optimal price allocation to researchers. This paper focuses on the design of a simple model based on Zhang \& Jasimuddin's equation that represents the dynamics of researchers' interest in answering questions in a specific kind of online knowledge market. The model shows this behavior of researchers. Furthermore, implementation of this model results in generating new and useful insights about the policy option analysis for developing new strategies in same knowledge markets.
\end{abstract}

Keywords: Online knowledge market, System dynamics model, Pricing strategy, Question \& answer (Q\&A) markets

\section{Introduction}

In recent years, along with the development of Internet technology, eCommerce has become increasingly modern. This development has changed the shopping behavior of customers as well as the ways that firms are doing business. A recent eGlobal report indicates that as access to the Internet improves all over the world, the number of active (those who are online at least 1 hour per week) users is more than about 640.2 million in 2004 (eGlobal Report, 2005). The TNS report also shows that U.S. is the nation with the greatest proportion of Internet users in the world who are engaged in online shopping. A helpful categorization of the key important factors for Internet shopping is identified by Shim et al. (2001) including transaction services (security, product guarantees, safety, privacy, and service), convenience (overall speed of Internet shopping and freedom from hassles), sensory experiences (the social, personalizing, and recreational experiences of shopping) and merchandise (product information, comparative shopping opportunities, and variety of merchandise choice).

Matson et al. (2003) depicted that in almost every organization there is an internal knowledge market where knowledge experts and knowledge seekers interact electronically to exchange their knowledge continuously. In these special markets, there is not any transaction of physical goods, but the buyers set their prices for their knowledge, and sellers choose from available offers from buyers to make transaction.

Nowadays, there are a variety of online knowledge markets available in the Internet, like Experts-exchange.com, Intota.com, InfoRocket.com, Kasamba.com, Knexa.com, Keen.com, eBrainx.com, Liveadvice.com, Allexperts.com, and Swapsmarts.com. For example, Experts-exchange is specialized service for computer technology related issues 
such as software programming, device troubleshooting, and etc.

Among these markets, Google Answers (GA) is a fee-based information market where experts sell their expertise to askers for a price quoted by the askers. It is one kind of knowledge market or a kind of question-and-answer service (Roush 2006). At GA, customers post their questions and set a price between $\$ 2$ and $\$ 200$ for that question. Free sharing of information in the form of comments takes place alongside the information trades by other registered users. Secondly, researchers which are hired by Google browse all the posted questions and choose whether or not to answer the questions based on their own judgments. A question can only be answered by one researcher and once the answer is complete, $75 \%$ of the price for the question belongs to the researcher, and the other $25 \%$ will remain to Google as its maintenance fee.

This paper presents a simple system dynamics model to depict and analyze the dynamics of researchers' behavior in this kind of knowledge market. The rest of the paper is sets out as follows. The next section considers the previous literature on knowledge markets and system dynamics methodology. Following that, are explanations about the model. Finally, the results are depicted and one scenario is analyzed.

\section{Knowledge Markets}

Just like any other market, knowledge market is a market in which some transactions are being made with this difference that goods are intangible. There is buyer and seller as the same as tangible goods market, where they can get the satisfied price by bargaining back and forth, and where there is an intermediary who can promote trading (Moodysson \& Jonsson, 2007; Winter, 2003). Knowledge market is defined as "an environment where buyers and sellers can trade their know-how within defined pricing and trading rules" (Desouza, et al., 2005). Because both buyers and sellers in knowledge market believe they can get some forms of benefit, some trading exists in knowledge markets (Merx et al., 2005). Despite the fact that there is not cash flowing in trading, there is price system in the market. It is the effective operation of knowledge market, which brings the knowledge flowing inside the knowledge net and realizes the sharing of knowledge (Huggins et al., 2008).

Davenport and Prusak (1998) introduced the concept of internal knowledge market within organizations, and they propose to employ the necessary information technology support as well as the crucial encouragements to build an effective internal knowledge market for knowledge transfer in organization.

After the early idea of knowledge market within organizations, Ba (2001) express that knowledge components can be optimally traded with a Grove-Clarke-like mechanism within different bundles in an internal organization market so that a firm can optimally choose the knowledge bundles for investment. Following that, Desouza et al. (2005) develop a mathematical analytics to show the feasibility of the market mechanism for knowledge management in organizations. Bakos (1997) discusses an online marketplace as a special type of electronic marketplace and proposes that electronic marketplaces reduce inefficiencies by lowering buyers' cost to obtain information about sellers' prices and product offerings.

Several studies (Edelman, 2004; Zhang \& Jasimuddin, 2008; Kenney et al., 2003; Chen et al., 2008; Rafaeli et al., 2005) have recently attempted to study the impact and implications of an online knowledge market from the inspirations of Google Answers. However, these studies have not investigated the working mechanism behind an online knowledge market, which is, the pricing strategies of consumers and Google who maintains the online knowledge market.

Zhang \& Jasimuddin (2008) suggest a mathematical and non-dynamic model for investigating the working mechanism behind an online knowledge market, that is, the pricing strategies of consumers and the firm who maintains the online knowledge market.

\section{System Dynamics}

The idea of System Dynamics (SD) was first introduced by J. W. Forrester (1961) in the 1960s at the Massachusetts Institute of Technology (MIT). SD was one of the very first responses to the insufficiency of Operation Research (OR) and other management science methodologies for solving complex problems with large number of variables, nonlinearity and human intervention. Based on former models and tools used by control engineers to analyze the stability of mechanical and electrical control systems (Tustin, 1953), he developed a set of tools and a powerful method for modeling and analyzing complicated problem situations. SD is mainly built upon traditional management of social system, cybernetics and computer simulation.

SD combines human mind and the power of computer in order to learn about dynamic complexity, limited information of problem situation, confounding variables and ambiguity, bounded rationality, flawed cognitive maps, wrong inferences about dynamics, and judgmental mistakes. In SD viewpoint, the behavior of a system is basically caused by its structure and policies. Thus, the structure of an organization is best represented with underlying flows of different resources as well as a variety of feedback loops and delays.

A SD model is normally consists of "causal-loop diagram (CLD)" and "flow diagram". The casual relationship shows 
that one element is affecting another one. A CLD is used to model this king of causality relationships. CLD requires additional positive (+) and negative (-) polarity to show the feedback structure of the related elements. For example, as shown in Figure 1 if the "number of employees calling sick" increases then the "number of employees available to work" would decrease. On the other hand, if the "number of employees calling sick" decreases then the "number of employees available to work" would definitely increase.

In Figure 1, the positive polarity is shown. We can also have a negative causal relationship as depicted in Figure 2. In this example, we consider that if the "number of employees available to work" increases then "Productivity" would increase. And also if the "number of employees available to work" decreases then "Productivity" would decrease too.

Another important diagram which SD uses to show the behavior of system is the "Stock-flow Diagram (SFD)". SFD shows the two variables which are required for simulating all elements inside a system, "level" and "rate". The level refers to a given factor within a specific time period, e.g. inventory level on March 2008 and so on. But, the rate reflects the extent of behavior of a system, such as hourly production amount, and monthly sales turnover.

\section{System Dynamics Model of Online Knowledge Market}

This section outlines a dynamic model which is build based on the previous analytical model by Zhang \& Jasimuddin (2008) and shows some initial results for further analysis. In this model, because customers do not know before setting the prices, who will ultimately answer their questions, they may always price their questions as suggested by the guidelines of Google Answers which is as follows: "The more research required to find an answer, the higher the price you should set for your question... Setting a price too low to compensate for the time required may result in your question not receiving an answer. The more you are prepared to pay, the more likely your question is to get answered quickly." This guideline can represented a simple causal structure which is depicted in Figure 3.

Figure 3 shows that a question with more research required should be placed with a higher price, or in other words, an increase (decrease) in a question's required research causes an increase (decrease) in the price of that question. Along with this fact, an increase in price would also cause an increase in the chance of getting answers quickly.

When a question is posted on the knowledge market, all the researchers will have the same chance to answer it. On the other hand, a more difficult question requires a researcher to have a higher knowledge level or apply more attempts to answer it. A question $m$ has its type $q_{m}$ of difficulty which is distributed with the probability function $H\left(q_{m}\right)$ between 0 and 1. As proposed by Zhang \& Jasimuddin (2008), a researcher tries to maximize his(her) total surplus by determining whether or not to answer the questions he(she) observes on the market. For a specific question $m$ priced at $p$, if he(she) answers it, a researcher will get a net payoff (total payoff) as

$\pi_{r}=\alpha p-\theta\left(p, k_{i}\right) \cdot q_{m}$

Where $\alpha$ is the proportion of price which is allocated to researchers for answering each question with price $p$ and $\theta\left(p, k_{i}\right)$ is the disutility a researcher with knowledge level $k_{i}$ will encounter by answering this question, including the effort cost and the risk of getting a bad assessment. Figure 4 depicts the causal structure of researchers' behavior.

Based on Equation 1 and its description, Figure 4 shows the causal structure of researchers' behavior and also demonstrates the influences over the total payoff. As depicted, a researcher with more knowledge would have more disutility to answer a question, and thus he(she) should have less total payoff for choosing the posted question. On the other hand, the price of a posted question has two direct and indirect influences upon total payoff. The indirect influence is when a customer sets a higher price for her(his) question, thus a researcher with a determined level of knowledge would have a more disutility to answer that question. Also the direct influence is when a question has a higher price, researcher would have more total payoff about that question because they are going to be paid more. The other two causes are the proportion which goes to the researcher and question's complexity level. When researcher's proportion is higher, he(she) would have paid more for answering the question. Finally, a more complex question would be of little interest to the researchers, though it would cause in lower total payoff.

Figure 5 depicts a simple stock-flow diagram for the causal structure which is shown in Figure 4 and its related equations are given in Appendix. This model represents the behavior of researchers' interest in locking a question and thus starting to find the answer in a limited time. In this model, it is assumed that there are 100 questions which are posted to the knowledge market and researchers decide weather to lock it or not in every 15 minutes in a period of 100 hours. This means that at every 15 minutes, a researcher came to the market and decides to lock a question. Total payoff is the key concept which determines the locking activity in this simple model. Along with that, knowledge level, complexity of question, and proposed price are important issues which are randomly generated for understanding the behavior. Proportion of researcher is a user-defined variable and it is set to 0.75 which means that $3 / 4$ of the question's price goes to the researcher. The model is simulated and the results are shown in Figures 6, and 7.

As depicted in Figure 6, this simulation shows if a researcher is free every 15 minutes in a period of 100 hours and other 
elements are randomly generated, only 43 questions out of 100 are locked to be answered. It is now possible to change the proposition variable and study the behavior of the market. Figure 8 shows the simulation results under this simple scenario.

This results shows that when the proportion of the researcher is set to $0.6,075$ (default), and 0.9 , and all other variables are the same, locked questions are 36,43 , and 48 . As depicted, the model is very sensible to the proposition variable and how a firm which owns the market can change the locking rates.

\section{Further Research}

The next step is to develop this model with more dynamic elements of this market such as risk, reputation, tips \& stars, income, answer time, and answer quality. Figure 9 shows these elements in a more detailed causal loop diagram.

For a researcher, accepting (or locking) a question with a higher price would have cause in a more risk for answering that. This is often because of the customer's knowledge or expertise in the question's field and also this fact that customers know that a more complex question, needs more price. Accepting more risk would cause danger in reputation, and also more tips and stars which goes to a researcher causes in more reliability of that researcher.

After drawing a developed causal loop diagram for the market, a formal and quantitative model of the system should be built for analyzing the sensitivity of the parameters, and then doing some policy experiments. Therefore, a simulation model with complete equations, parameters, and initial conditions should exists in order to direct real world experiments with different parameter values and initial conditions, which often impractical and infeasible in real world due to a number of reasons. With use of this causal loop diagram, a formulized simulation model which is called stock-flow diagram is build as shown in Figure 10.

Future research by the authors will focus on developing, formulizing, and simulating this dynamic model over time that enables buyer, sellers, and the owners of online knowledge markets to study the behavior of market in different condition. Furthermore, there are many undefined parameters in this model which should be determined by field studies and other contributions.

\section{Conclusion}

The simple dynamic model to analyze researchers' interest in answering questions for an online question and answer (Q\&A) knowledge market was simulated for a specific kind of pricing in a knowledge market whereby some parameters are generate randomly and the basic model is based on Zhang \& Jasimuddin (2008)'s equation. The results are briefly discussed and the behavior of the model was analyzed under a specific scenario. The simulation was run for 100 hours. The model showed the behavior of locked/open questions. Implementing this model resulted in new and useful insights in the future of possible policies for developing new dynamic models for modeling and simulation of online question-and-answer (Q\&A) knowledge markets.

\section{References}

Ba, S., Stallaert, J. \& Whinston A. B. (2001). Optimal investment in knowledge within a frm using a market mechanism. Management Science, 47, 9, 225-239.

Bakos, Y. (1997). Reducing buyer search costs: Implications for electronic marketplaces. Management Science, 43, 12, 1676-1692.

Chen, Y., Hi, T.H. \& Kim, Y.M, (2008), Knowledge Market Design: A Field Experiment at Google Answers (Working Paper), [Online] Available: http://www.si.umich.edu/ yanchen (Feb 15, 2009).

Davenport, H. T. \& Prusak, L. (1998). Working knowledge: How organizations manage what they know. Boston, MA: Harvard Business School Press.

Desuoza, K., Awazu, Y., Yamakawa, S. \& Umezawa, M. (2005). Facilitating knowledge market mechanism. Knowledge and Process Management, 12, 2, 99-107.

Edelman, B. (2004). Earnings and ratings at Google Answers (Working Draft). Harvard Law School, Harvard University.

eGlobal Report, (2005), [Online] Available: www.eMarketer.com (Feb 2, 2009).

Forrester, J. W. (1961). Industrial Dynamics. Cambridge, MA: MIT Press.

Huggins, R., Johnston, A. \& Steffenson, R. (2008). Universities, knowledge networks and regional policy[J]. Cambridge Journal of Regions, Economy and Society, 1, 2, 321-340.

Kenney, A. R., McGovern, N. Y., Martinez, I. T. \& Heidig, L. J. (2003). Google meets eBay-What academic librarians can learn from alternative information providers. D-Lib Magazine, 9, 6.

Moodysson, J. \& Jonsson, O. (2007). Knowledge Collaboration and Proximity. European Urban and Regional Studies, 


\section{$14,2,115-131$.}

Merx, M. Nijbof, W. J. (2005). Factors Influencing Knowledge Creation And Innovation in an Organization. Journal of European Industrial Training, 29, 2, 135-147.

Matson, E., Patiath, P. \& Shavers, T. (2003). Stimulating knowledge sharing: Strengthening your organization's internal knowledge market. Organizational Dynamics, 32, 3, 275-285.

Roush,W. (2006). What's the Best Q\&A Site?, MIT Technology Review, December 2006.

Rafaeli, S., Daphne R. R. \& Ravid, G. (2005) Social and economic incentives in Google Answers, in ACM Group 2005 Conference, ACM November 2005.

Shim, S., Eastlick, M.A., Lotz, S.L. \& Warrington. (2001). An online pre-purchase intentions model: the role of intentions to search. Journal of Retailing, 77, 397-416.

Tustin, E. (1953). The Mechanism of Economic Systems. Cambridge, MA: Harvard University Press.

Winter S. (2003). Understanding Dynamic Capabilities. Strategic Management Journal, 10, 991-995.

Zhang, Z. \& Jasimuddin, S. M. (2008). Pricing strategy of online Knowledge Market: the analysis of Google answers, International Journal of E-Business Research, 4, 1, 55-68.

\section{Appendix}

System dynamics model equations:

01) Complexity of Question=

$$
\text { RANDOM UNIFORM( } 0.01,1,0.1)
$$

02) FINAL TIME $=100$

Units: Hour

The final time for the simulation.

03) INITIAL TIME $=0$

Units: Hour

The initial time for the simulation.

04) Knowledge Level=

RANDOM NORMAL $(0,1,0.5,0.1,0.1)$

05) Lock Rate=

IF THEN ELSE(Total Payoff $>0$, IF THEN ELSE(Questions $>0$, 1, 0), 0)

06) Locked Questions = INTEG (

+Lock Rate,

$0)$

07) Proportion of Researcher=

0.75

08) Proposed Price $=$

RANDOM UNIFORM( $0.01,1,0.1)$

09) Questions = INTEG (

-Lock Rate,

100)

10) TIME STEP $=0.25$

Units: Hour [0,?]

The time step for the simulation.

11) Total Payoff=

Proportion of Researcher*Proposed Price-(Knowledge Level/Proposed Price)*

Complexity of Question 


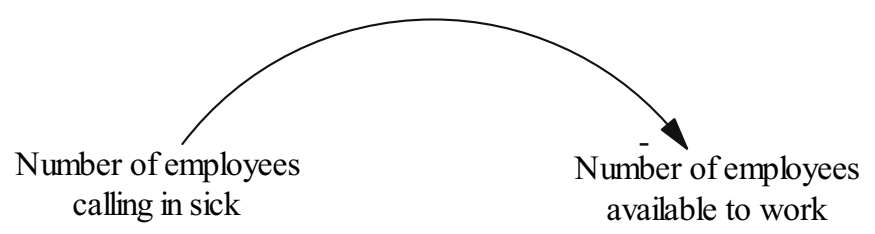

Figure 1. Positive causal relationship

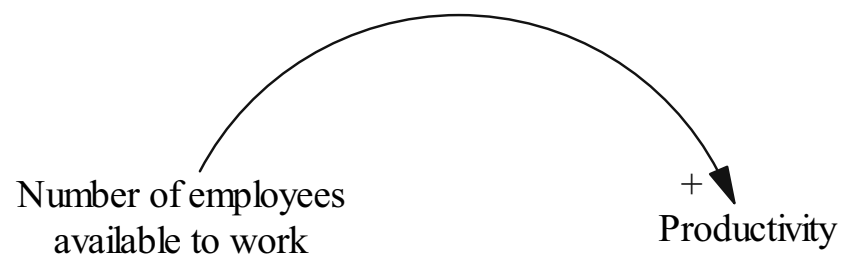

Figure 2. Negative causal relationship

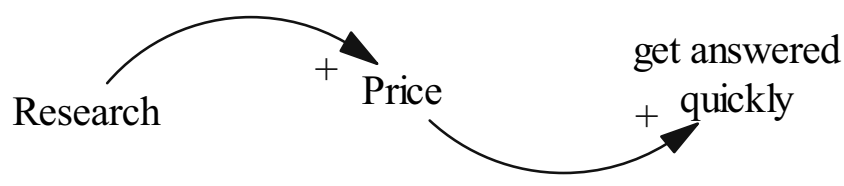

Figure 3. Causal loop diagram of determining a base price for a question by customer

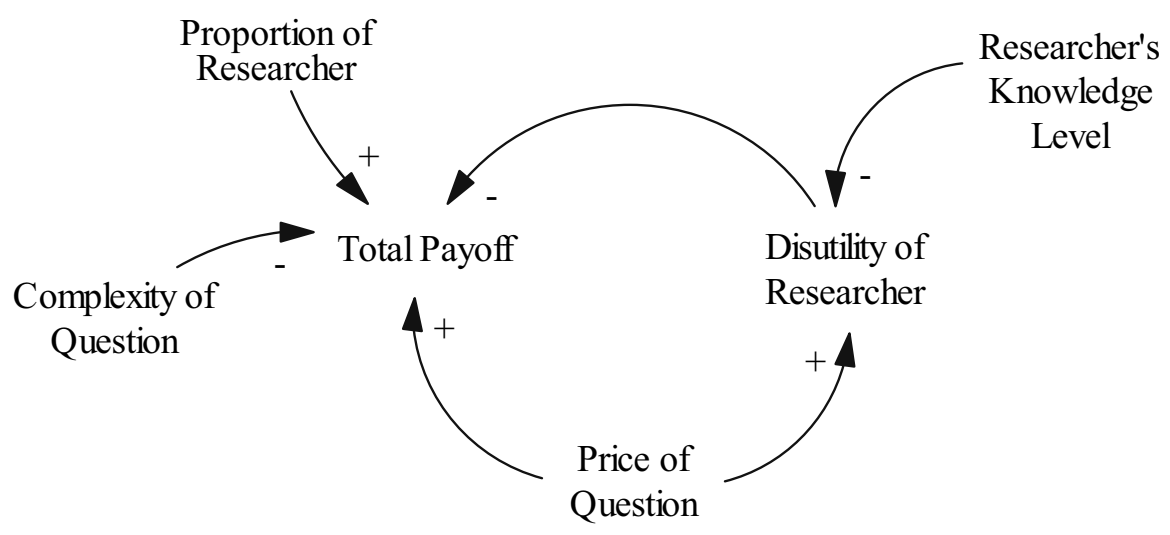

Figure 4. Causal loop diagram of researchers' behavior 


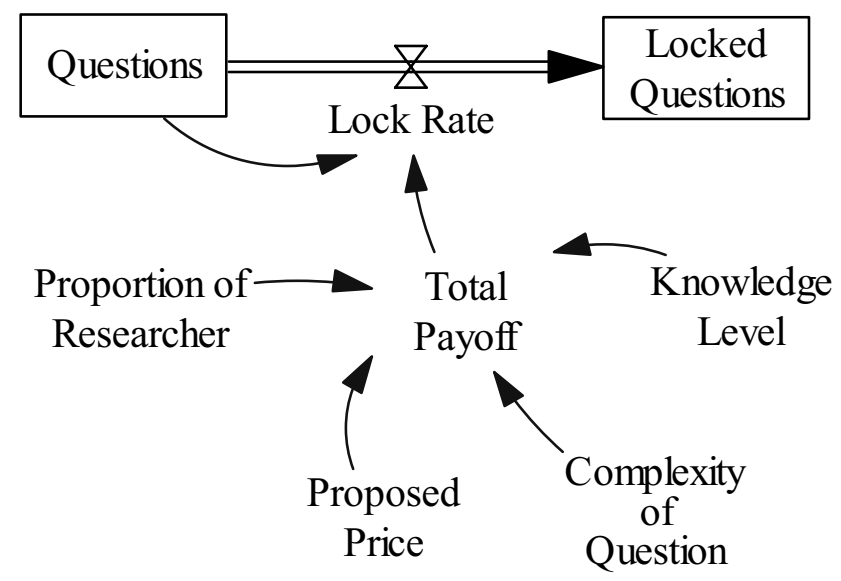

Figure 5. Simple Stock-flow diagram (simulation model) of researchers' interest in locking a question

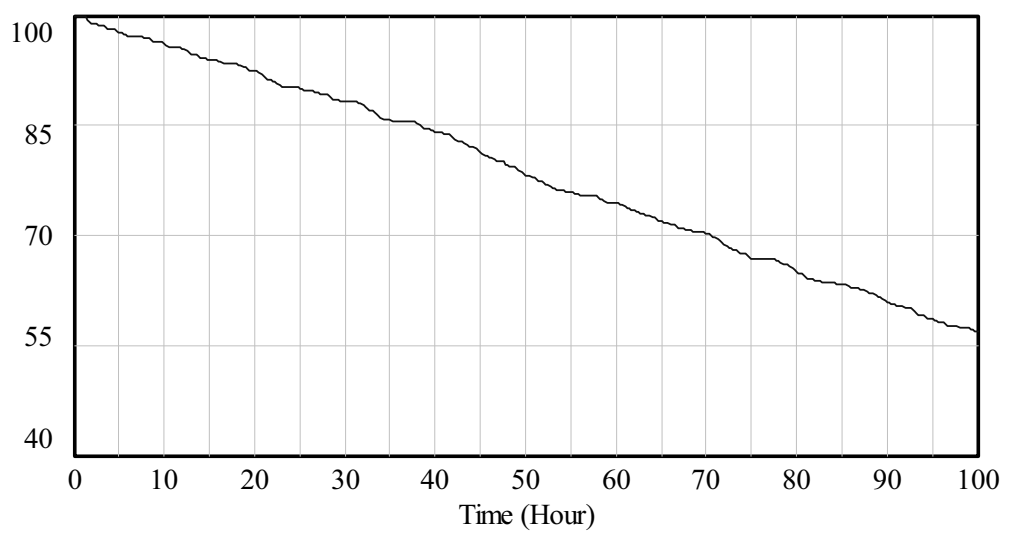

Figure 6. Unlocked (Open) questions in the market

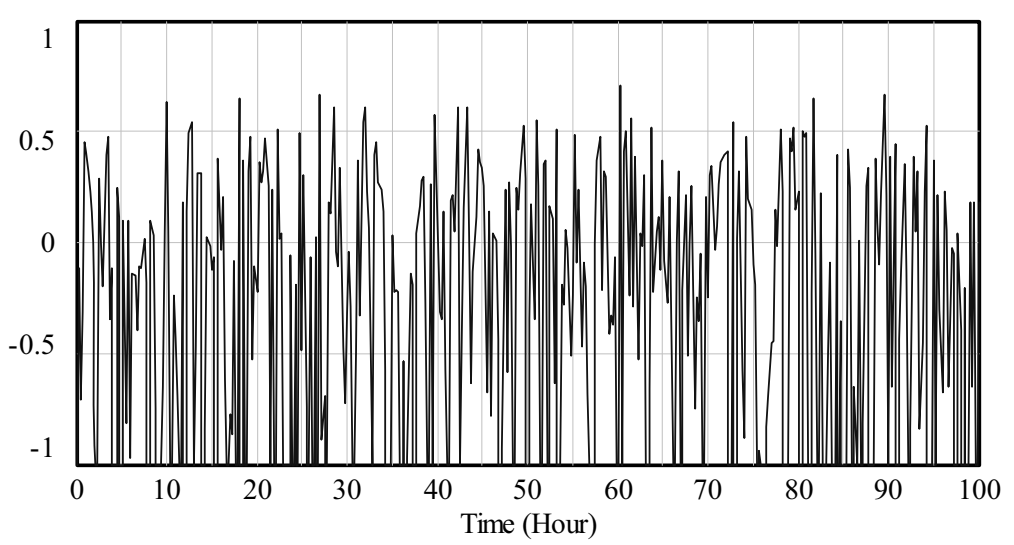

Figure 7. Total payoff for researchers in 100 hours period 


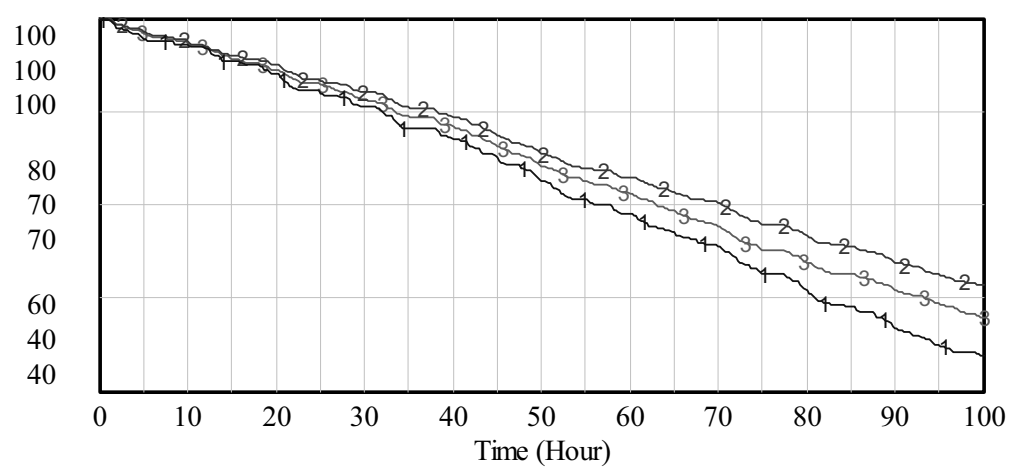

Proportion of researcher is 0.6
Proportion of researcher is 0.75

Figure 8. Unlocked (Open) questions in the market under a simple scenario

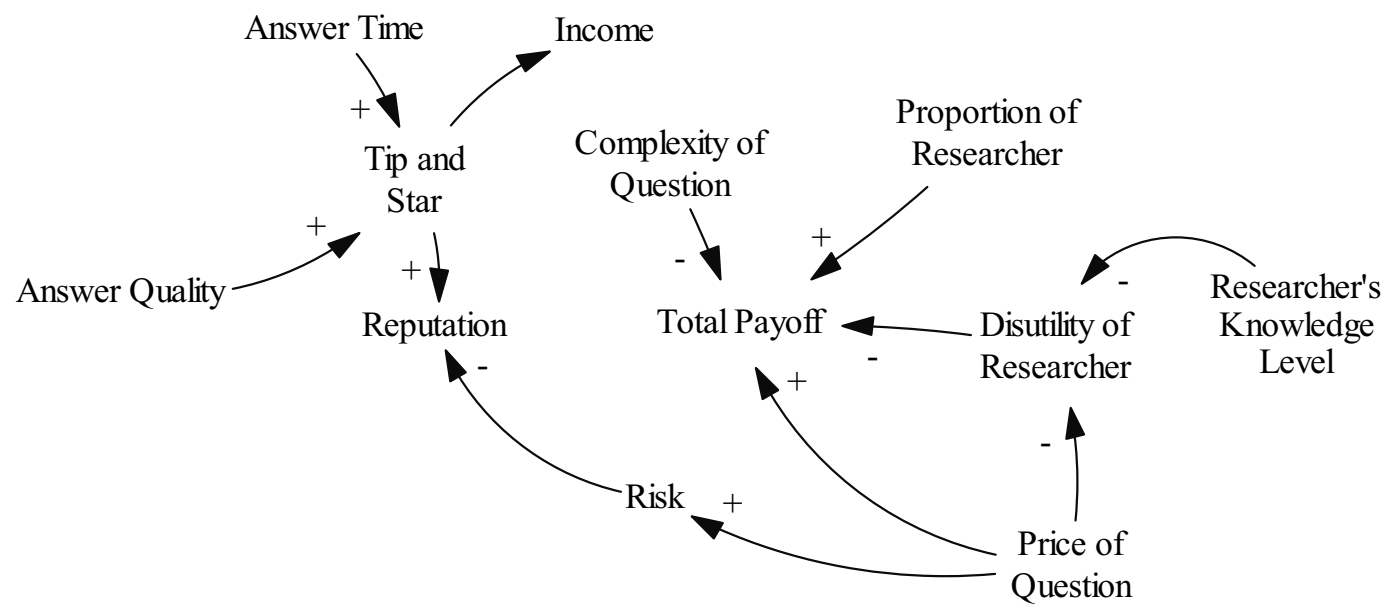

Figure 9. More developed causal loop diagram of researchers' behavior

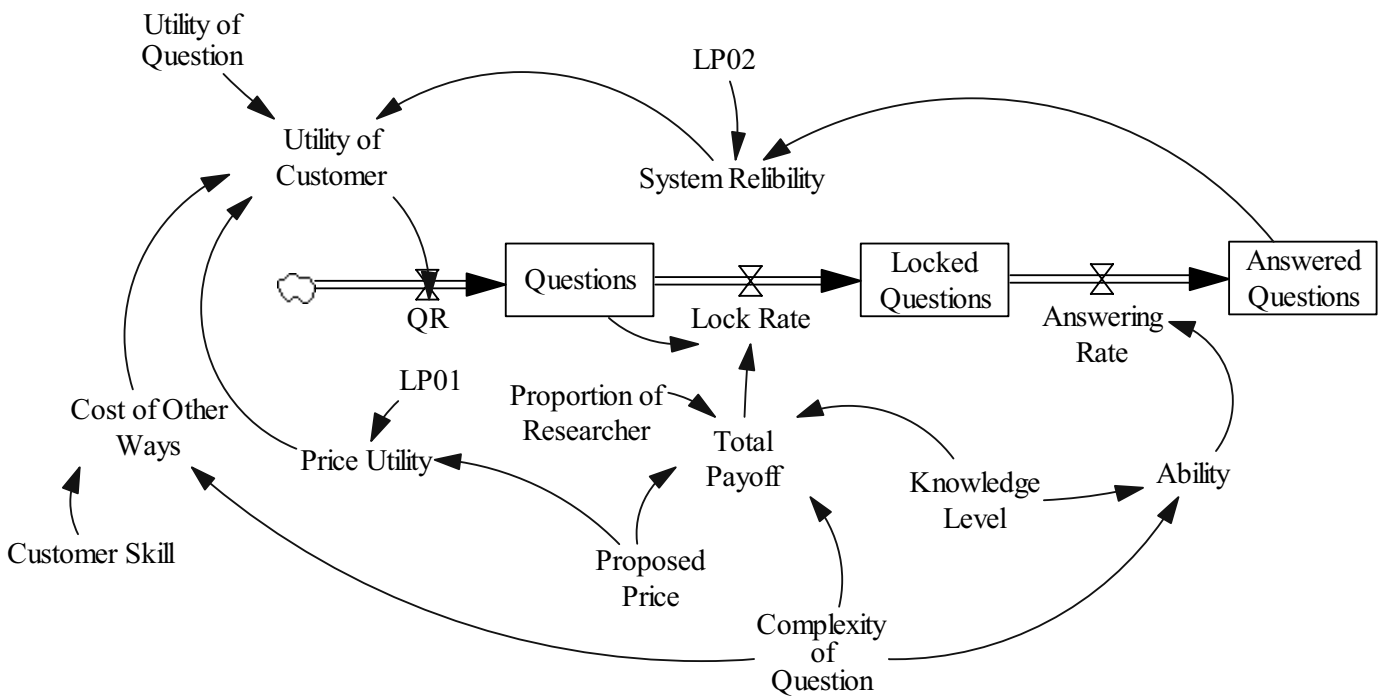

Figure 10. Stock-flow diagram of locking and answering behavior 